\title{
A NEW APPROACH TO LOCALIZE GLUCOCORTICOID RECEPTOR USING DNA PROBE CONTAINING GLUCOCORTICOID RESPONSIVE ELEMENT DNA CONSENSUS SEQUENCES
}

\author{
Takehiko KOJI, Shuhei YAMADA*, Kenichi KAYAShima and Paul K. NAKANE
}

Department of Anatomy, Nagasaki University School of Medicine, Sakamoto, Nagasaki 852

\begin{abstract}
A method to localize glucocorticoid receptor (GR) by utilizing the specific interaction between GR and glucocorticoid responsive element (GRE) is described. In this study, pBR 322 DNA was thymine-thymine (T-T) dimerized by UV-irradiation and used as a probe, since pBR 322 DNA harbors GRE DNA consensus sequences and it is known that GR binds to pBR 322 DNA specifically. T-T dimerized pBR 322 DNA was incubated with fresh frozen sections of adrenalectomized rat liver, which were fixed in $4 \%$ paraformaldehyde in phosphate buffered saline, and the sites of reaction were visualized by a successive use of rabbit anti-T-T antibody and horseradish-peroxidase labeled goat anti-rabbit IgG antibody. As a result, GR was localized to the nuclei and nuclear membranes as well as cytoplasm of hepatocytes, and most of the staining was lost in the liver sections from rats, which were intraperitoneally injected with hydrocortisone. On the other hand, the staining for T-T dimerized DNA probe with cyclic AMP responsive element consensus sequence was localized solely to the nuclei and the staining pattern was not altered by an injection of the steroid, indicating that the staining for $\mathrm{PBR} 322$ DNA is sequence-specific. Finally, this method should provide useful information on the localization of steroid hormone receptors with DNA-binding activity.
\end{abstract}

Steroid hormones affect target cells through a binding to their receptors. Thus, for a better understanding of the hormone-dependent phenomenon occurring in individual cells, it is essential to analyze the state of the receptors at an individual cell level. Moreover, since both molecular architecture and cellular localization of the receptors (or the receptor complexes) are easily altered by the conventional biochemical isolation procedures $(4,8)$, a histochemical method is apparently appropriate for the above purpose.

Recently, by using antibodies against steroid receptors, much progress in our knowledge on the localization of the receptors has been made (14). However, it is well documented that steroid hormone receptors change their conformation during signal transduction pathway of hormones, followed by the changes in the functional state of receptors (36). Therefore, the immunohistochemical localization of receptors is not sufficient to characterize the functional

\footnotetext{
* Present address: Department of Internal Medicine, Shinshu University School of Medicine, Matsumoto 390.
}

state of the receptors in situ.

Steroid hormone receptors belong to a family of trans-acting transcriptional activation factors and consist of three autonomous domains; trans-activation domain, DNA-binding domain and hormone-binding domain $(9,21,23)$. The receptors regulate gene expression through their binding to specific DNA sequences located in the vicinity of the regulated gene (2). Thus, DNA binding capacity is a prerequisite for the receptor function.

Glucocorticoid receptor (GR) has been the first transcription factor to be isolated and studied in detail (23). The glucocorticoid responsive element (GRE) DNA sequences of various genes $(12,22,26,30,32)$ have been identified, and it has been known that a bacterial plasmid pBR 322 DNA contains these GRE core sequences at five sites and binds to GR on Southwestern blots (33). In addition, we have observed a specific staining for $\mathrm{pBR} 322$ DNA in rat pituitary sections (15), the pattern of which is similar to that of GR immunostaining (1).

Based on the accumulated data, we tried to localize GR with DNA-binding activiy in rat liver sec- 
tions using thymine-thymine (T-T) dimerized $\mathrm{pBR}$ 322 DNA $(15,17,24)$. The T-T dimers, after reaction with the sections, were detected enzyme-immunohistochemically. When the frozen sections of livers from adrenalectomized rats were used, the staining for T-T dimerized pBR 322 DNA was found in the nuclei, nuclear membranes as well as cytoplasm of hepatocytes. However, the staining was much decreased in the rat livers with glucocorticoid administration.

A part of this study has already appeared in abstract form (18).

\section{MATERIALS AND METHODS}

Materials: Hydrocortisone, dibutyryl cyclic AMP ( But $_{2}$ cAMP), and theophylline were purchased from Sigma Chem. Co., USA; pBR 322 DNA and Hind III were from Toyobo Co., Japan; paraformaldehyde (PFA) was from Merck, FRG; horseradish peroxidase labeled goat anti- (rabbit IgG) Fab was from Medical Biological Laboratory, Japan. All other chemicals used in this study were of analytical grade.

Animal: Wistar male rats weighing $150-160 \mathrm{~g}$ were used. In order to minimize the effects of endogenous glucocorticoid hormone $(1,8)$, all rats used here were adrenalectomized. Two days after adrenalectomy, they were injected intraperioneally with hydrocortisone $(10 \mathrm{mg} / 100 \mathrm{~g}$ b.w., $1 \mathrm{ml} / \mathrm{head})$ dissolved in saline, a mixture (1 ml/head) of But ${ }_{2}$ cAMP $(5 \mathrm{mg} /$ $100 \mathrm{~g} \mathrm{b.w.)}$ and theophylline $(2 \mathrm{mg} / 100 \mathrm{~g} \mathrm{b.w.)}$ in saline, or saline alone ( $1 \mathrm{ml} / \mathrm{head})$. Two hr later, they were killed by cervical dislocation, and the livers were excised and quickly frozen with OCT compound. It had been known that a significant effect of those compounds was elicited within $2 \mathrm{hr}$ after injection $(13,25)$. Probe DNA and T-T dimerization: pBR 322 DNA was dissolved in $10 \mathrm{mM}$ Tris- $\mathrm{HCl} / 1 \mathrm{mM}$ EDTA ( $\mathrm{pH} 7.4$ ) at a concentration of $50 \mu \mathrm{g} / \mathrm{ml}$ and T-T dimerized with $\mathrm{UV}$-irradiation at a dose of $7,000 \mathrm{~J} / \mathrm{m}^{2}$, as described previously $(17,24)$. The sites of GRE DNA consensus sequences in pBR 322 DNA have been shown by Tully and Cidlowski (33). A single site (4,044-4,051) satisfied the constraints of GRE sequence in the MMTV-LTR (26) and the sequence 5'-TGTTCT-3' $(30,32)$ was found at two sites $(1,376-1,381$ and $2,472-2,477)$ and the sequence 5 '-TGTCCT- $3^{\prime}(11$, 21) was also found at two sites (760-765 and 2,9752,980). The T-T dimerized PBR 322 DNA was linearized by digestion with Hind III, which dose not cut the GRE sequences.

An oligodeoxynucleotide (TTATTATTATGA CGTCA) containing cyclic AMP responsive element
(CRE) consensus sequence (10) was synthesized by $\beta$ cyanoethylphosphoramidite method on a DNA synthesizer (Cyclon, Biosearch Inc.), and used as a control probe after self-annealing and $\mathrm{T}-\mathrm{T}$ dimerization as described above.

Tissue treatment: The following experiments were done at room temperature $\left(25-28^{\circ} \mathrm{C}\right)$, unless otherwise specified. Fresh frozen sections $(5 \mu \mathrm{m})$ were cut, put to gelatin-coated glass slides $(15,17)$, and air-dried for $1 \mathrm{hr}$. The sections were immersed in cold acetone $\left(-20\right.$ or $\left.4^{\circ} \mathrm{C}, 10 \mathrm{~min}\right)$ or $4 \% \mathrm{PFA}$ in phosphate buffered saline (PBS) $\left(\mathrm{pH} \mathrm{7.4)}\left(4^{\circ} \mathrm{C}, 10 \mathrm{~min}\right)\right.$, and rinsed with PBS. The sections were preincubated with $50 \mathrm{mM}$ Tris- $\mathrm{HCl}$ buffer $(\mathrm{pH} 7.4)$ containing $5 \%$ nonfat dry milk, $50 \mathrm{mM} \mathrm{NaCl}$ and $1 \mathrm{mM}$ EDTA for $1 \mathrm{hr}$. Then the specimens were incubated overnight with $\mathrm{T}$ T dimerized pBR 322 DNA $(5 \mu \mathrm{g} / \mathrm{ml})$ or T-T dimerized CRE oligodeoxynucleotide $(5 \mu \mathrm{g} / \mathrm{ml})$ dissolved in the preincubation medium, and were washed with the preincubation medium (twice, 15 min each) and with PBS (three times, 15 min each), successively.

Immunohistochemistry: T-T dimers were localized enzyme-immunohistochemically, as described in the previous paper $(15,17)$.

\section{RESULTS}

As a first step, we compared the effects of fixation with cold acetone and 4\% PFA/PBS on the signal detection in fresh frozen sections. In acetone-fixed sections, we got only a faint staining for pBR 322 DNA probe mainly in littoral cells (data not shown). As more convincing results were obtained in the sections fixed with $4 \%$ PFA/PBS, the cross-linking fixative was used in the following experiments.

When the liver sections from the control rats were incubated with pBR 322 DNA probe, the nuclei of hepatocytes were stained punctuately, as shown in Fig. 1-a. Moreover, the nuclear membranes as well as cytoplasm of hepatocytes were also stained. When hydrocortisone was injected into rats, however most of the staining observed in the sections from the control rats disappeared (Fig. 1-b), though still a very faint, but significant punctuated staining of nuclei still remained. On the other hand, the administration of But $_{2}$ cAMP together with theophylline did not alter the general pattern of the staining for the probe (Fig. 1-c).

Since by computer-searching we found that $\mathrm{pBR}$ 322 DNA contains single CRE site, the staining observed above may be ascribed to CRE binding protein. To assess the possibility, T-T dimerized CRE oligodeoxynucleotide was reacted with the same set of rat liver sections. As shown in Fig. 2, a strong 
nuclear, but not cytoplasmic, staining was observed in the liver sections from the control rats (Fig. 2-a). Contrary to the result with $\mathrm{pBR} 322$ probe, the staining for CRE probe was not altered by an injection of hydrocortisone (Fig. 2-b), while the staining was markedly reduced by an injection of $\mathrm{But}_{2} \mathrm{CAMP}$ and theophylline (Fig. 2-c).
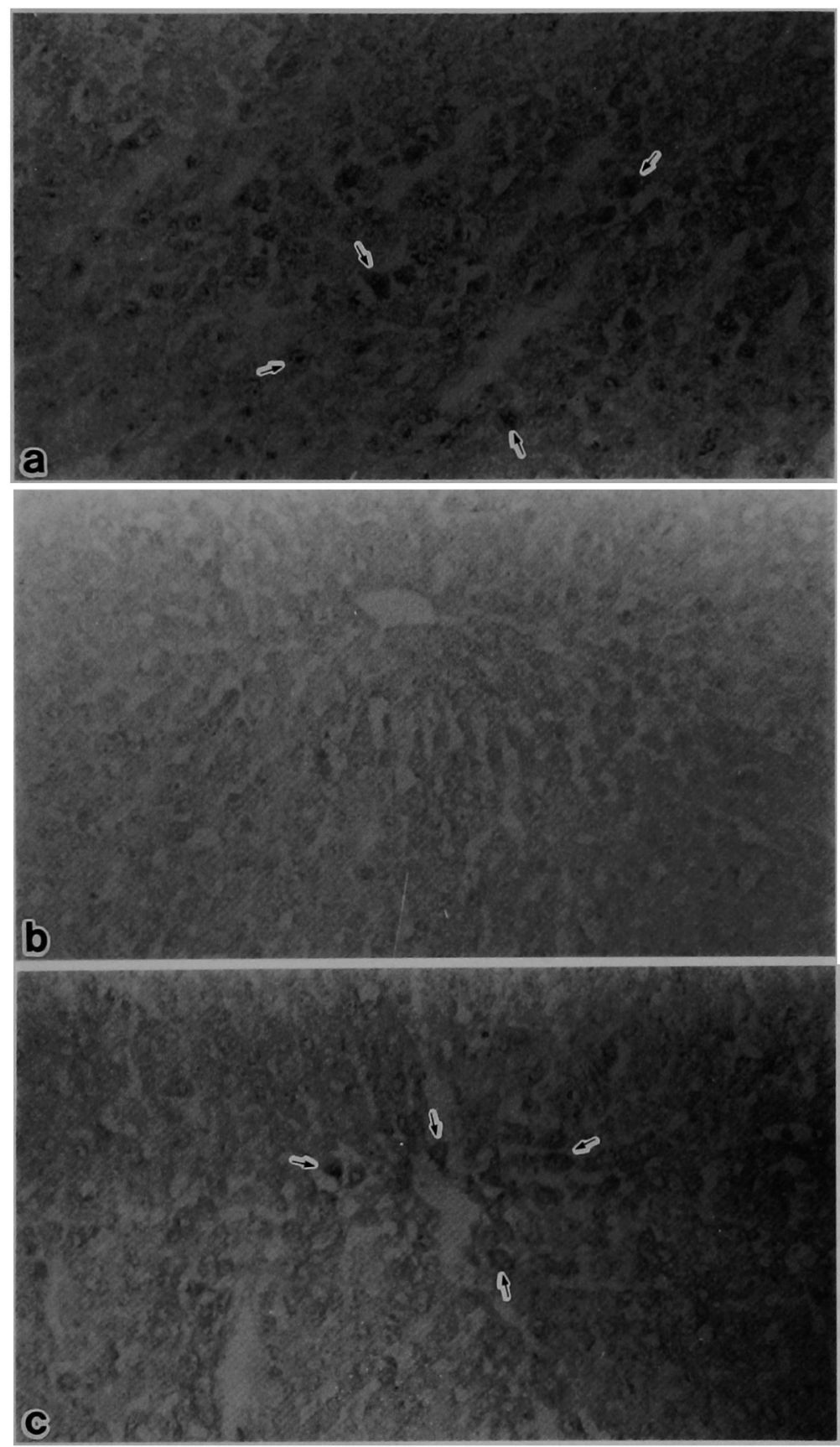

FIGs. 1a-c. Localization of GR with PBR 322 DNA in fresh frozen sections of livers from adrenalectomized rats. The liver sections from adrenalectomized rats, which were injected intraperitoneally with saline (a), hydrocortisone (b), or a mixture of But ${ }_{2}$ cAMP and theophylline (c), were reacted with T-T dimerized pBR 322 DNA, and the signals were detected enzyme-immunohistochemically. The positive hepatocytes were indicated by arrows. $\times 200$ 


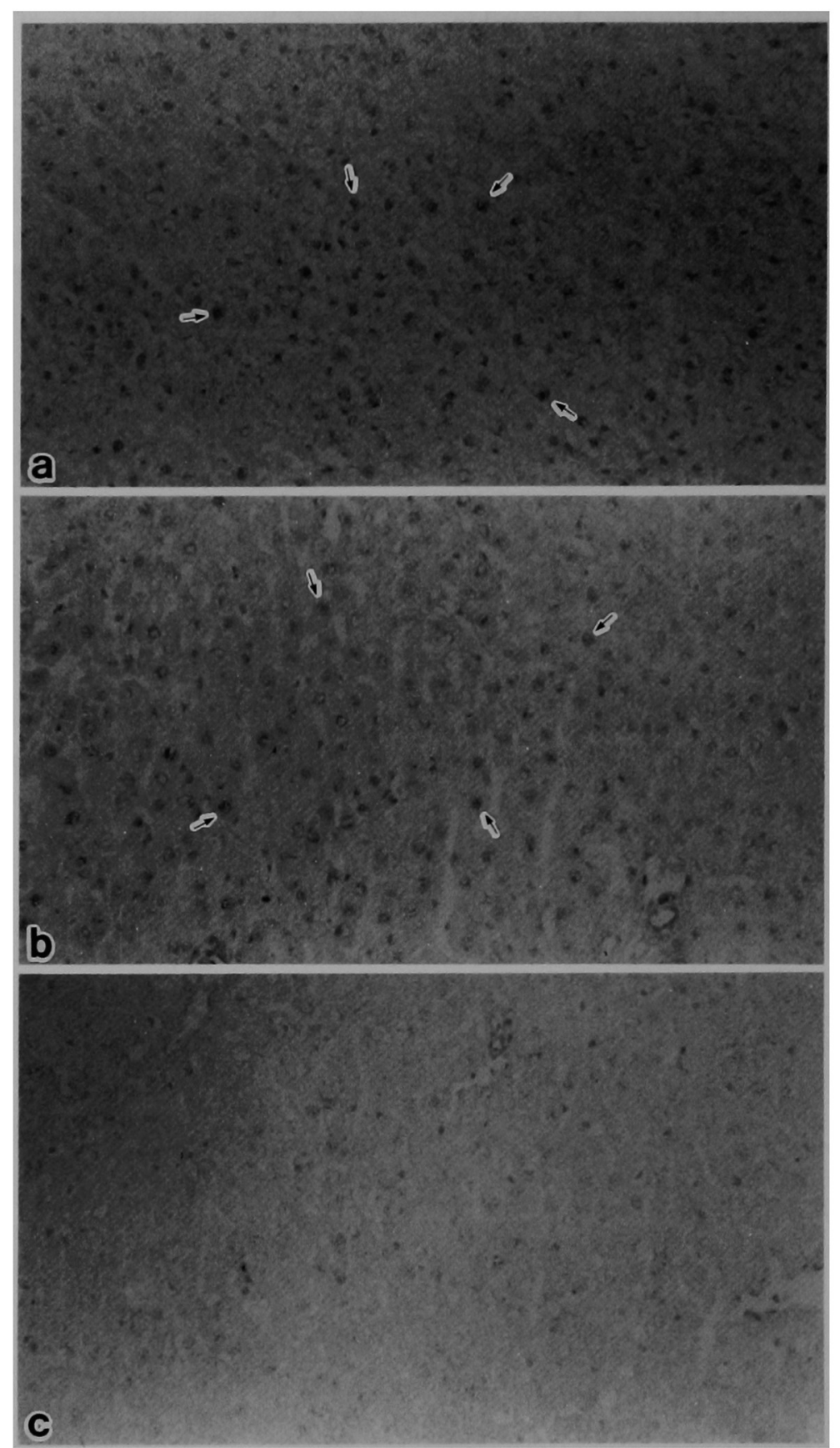

Figs. 2a-c. Localization of the staining for CRE oligodeoxynucleotide in fresh frozen sections of livers from adrenalectomized rats. The liver sections from adrenalectomized rats, which were injected intraperitoneally with saline (a), hydrocortisone (b), or a mixture of But 2 cAMP and theophylline (c), were reacted with T-T dimerized pBR 322 DNA, and the signals were detected enzyme-immunohistochemically. The positive hepatocytes were indicated by arrows. $\times 200$

\section{DISCUSSION}

In this paper we attempted to develop a method for localizing GR by utilizing the nature that GR specifically binds to the DNA with the GRE se- quences. The reason why we used $\mathrm{pBR} 322 \mathrm{DNA}$ as a probe is based on the findings that haptenized pBR 322 DNA gives rise to a staining, whose localization is similar to that of GR in rat pituitary sections (15), and that pBR 322 DNA binds to GR in a Southwestern 
blot (33). In fact, $\mathrm{pBR} 322$ DNA contains in itself five GRE core sequences and three GRE-related sequences (33). Although some GRE sequences may be modified by UV-irradiation, the majority of the sequences is thought to remain to be effective under the irradiation conditions (24).

It seems to be a general concept that ligand-free GR is present solely in cytoplasm as an inactive complex with heat-shock protein (hsp)90 (7) and other cytosolic proteins $(27,31)$. Once GR binds glucocorticoid, then the complex dissociates, which allows the receptor to change its form and to be dimerized. Now the dimerized GR enters into nucleus and binds to specific DNA sequences with GRE, followed by activation of a certain gene (36). Although the activation process of GR has been well documented as stated above, our knowledge on the DNA-binding activity of the ligand-free unactivated GR is only limited. It is currently conceivable (23) that even though the binding of the unactivated GR to DNA is hindered in vivo by confinement to the cytoplasm or the association to hsp90 $(3,35)$, the potential to bind to the DNA is retained (34). As the method described here apparently utilizes the potential ability of the ligand-free GR to bind to the DNA, our results seem to indicate that, even if the DNA-binding activity of the ligand-free GR is hindered by hsp 90 and/or the other proteins in vivo, the binding activity can be exposed during the histochemical processing through dissociation of the unstable GR complex (5). In this context, it is worthwhile noting that in the absence of steroid binding and heat activation, in vitro synthesized human GR exhibited significant DNA-binding activity, suggesting an involvement of alternative mechanisms in expression of the activity rather than hsp90 dissociation (5).

Although our finding that ligand-free GR is present in the nuclei and nuclear membranes is inconsistent with the general concept, it should not be surprised since the results to support the localization of ligand-free GR in nuclei (8) as well as nuclear membranes (11) have been recently reported. Moreover, overexpressed GR has been demonstrated in nuclei (20), irrespective of the presence or absence of DNA binding domain or hormone binding domain. In the context, it should be noted that progesterone receptor $(4,8)$, estrogen receptor $(4,14)$ and androgen receptor $(28,29)$ are predominantly localized in nuclei, even in the absence of ligand.

We found also that most of the staining of GR disappeared after hydrocortisone injection. The hormone-dependent loss of the staining of GR may reflect the occupation of GR by the genomic endogenous GRE through the usual activation process, and/or the down-regulation of GR expression (1).

As pBR 322 DNA has single CRE sequence and $T$ - $T$ dimerized CRE oligonucleotide binds to CRE binding protein of nuclei (18), we cannot exclude the possibility of involvement of CRE binding protein in the observed staining. In practice, however, it seems unlikely that the staining for pBR 322 probe was largely due to CRE binding protein, because of a significant difference in both the staining patterns and the changes in the staining which were induced by the hormonal manipulation; the staining for CRE probe was predominantly localized to the nuclei, but not to the cytoplasm, and the staining was completely lost after administration of But $_{2}$ CAMP and theophylline (Fig. 2).

In addition, it has been suggested that GR is easily extracted from tissue sections. Gasc et al. (8) have recently reported that acetone pretreatment of frozen sections of adrenalectomized rat liver resulted in an almost complete loss of GR immunostaining. Our finding that the similar loss of the staining for $\mathrm{PBR} 322$ DNA occurred in the acetone-fixed sections seems to be consistent with the previous results (8).

Finally, a variety lines of indirect evidence seem to provide the method described here with the specificity required for the demonstration of GR. Thus, by extending the principle, the technique will be a useful tool to analyze the expression of proteins which bind to specific DNA sequences, in individual cells.

\section{REFERENCES}

1. Antakly, T., Raquidan, D., O'Donnell, D. and Katnick, L.: Regulation of glucocorticoid receptor expression: I. Use of a specific radioimmunoassay and antiserum to a synthetic peptide of the N-terminal domain. Endocrinol. 126; 1821-1828, 1990.

2. Beato, M.: Gene regulation by steroid hormones. Cell 56; 335-344, 1989.

3. Becker, P. B., Gloss, B., Schmid, W., Strahle, U. and Schutz, G.: In vivo protein-DNA interactions in a glucocorticoid response element require the presence of the hormone. Nature 324; 686-688, 1986.

4. Brenner, R. M., McClellan, M. C. and West, N. B.: Immunocytochemistry of estrogen and progestin receptors in the primate reproductive tract. In Steroid Receptors in Health and Disease, ed. by V.K. Moudgil, Plenum Publishing Corporation, 1988, p. 47-70.

5. Burnstein, K. L., Jewell, C. M. and Cidlowski, J. A.: Evaluation of the role of ligand and thermal activation on specific DNA binding by in vitro synthesized human glucocorticoid receptor. Mol. Endocrinol. 5; 1013-1022, 1991.

6. Dahmer, M.K., Housley, R. P. and Pratt, W. B.: 
Effects of molybdate and endogenous inhibitors on steroid-receptor inactivation, transformation, and translocation. Annu. Rev. Physiol. 46; 67-81, 1984.

7. Denis, M., Wikstrom, A.-C. and Gustafsson, J.-A.: The molybdate-stabilized nonactivated glucocorticoid receptor contains a dimer of $\mathrm{M}_{\mathrm{r}} 90,000$ non-hormone-binding protein. J. Biol. Chem. 262; 11803-11806, 1987.

8. Gasc, J.-M., Delahaye, F. and Baulieu, E.-E.: Compared intracellular localization of the glucocorticosteroid and progesterone receptors: An immunocytochemical study. Exp. Cell Res. 181; 492-504, 1989.

9. Green, S., Kumar, V., Krust, A., Walter, P. and Chambon, P.: Structural and functional domains of the estrogen receptor. In "Cold Spring Harbor Symposium on Quantitative Biology”, Vol. LI, Cold Spring Harbor Laboratory, 1986, p. 751-758.

10. Habener, J. F.: Cyclic AMP response element binding proteins: A cornucopia of transcription factors. Mol. Endocrinol. 4; 1087-1094, 1990.

11. Howell, G. M., Gustafsson, J.-A. and Lefebvre, Y. A.: Glucocorticoid receptor identified on nuclear envelopes of male rat livers by affinity labeling and immunochemistry. Endocrinol. 127; 1087-1096, 1990.

12. Karin, M., Haslinger, A., Holtgreve, H., Cathala, G., Slater, E. and Baxter, J. D.: Activation of a heterologous promoter in response to dexamethasone and cadmium by metallothionein gene 5'-flanking DNA. Cell 36; 371-379, 1984.

13. Kenney, F. T.: Induction of tyrosine- $\alpha$-ketoglutarate transaminase in rat liver. IV. Evidence for an increase in the rate of enzyme synthesis. J. Biol. Chem. 237; 34953498, 1962.

14. King, W. J. and Greene, G. L.: Monoclonal antibodies localize oestrogen receptor in the nuclei of target cells. Nature 307; 745-747, 1984.

15. Koji, T., Moriuchi, T. and Nakane, P. K.: Improved tissue preparation for in situ localization of specific mRNA using non-radioactive DNA probes: Effects of protease digestion and probe size on signal detection in frozen and paraffin sections of rat pituitary glands. Acta Histochem. Cytochem. 21; 187-200, 1988.

16. Koji, T., Sugawara, I., Kimura, M. and Nakane, P. K.: In situ localization of $c-m y c \mathrm{mRNA}$ in HL-60 cells using non-radioactive synthetic oligodeoxynucleotide probes. Acta Histochem. Cytochem. 22; 295-307, 1989.

17. Koji, T. and Nakane, P. K.: Localization in situ of specific mRNA using thymine-thymine dimerized DNA probes. Sensitive and reliable non-radioactive in situ hybridization. Acta Pathol. Jpn. 40; 793-807, 1990.

18. Koji, T., Yamada, S., Izumi, S. and Nakane, P. K.: Oligo histochemistry: A new approach to localize DNAbinding proteins. J. Histochem. Cytochem. 38; 1052, 1990.

19. Kurl, R. N. and Jacob, S. T.: Phosphorylation of purified glucocorticoid receptor from rat liver by an endogenous protein kinase. Biochem. Biophys. Res. Commun. 119; 700-705, 1984.

20. Martins, V. R., Pratt, W. B., Terracio, L., Hirst, M. A., Ringold, G. M. and Housley, P. R.: Demonstration by confocal microscopy that unliganded overexpressed glucocorticoid receptors are distributed in a nonrandom manner throughout all planes of the nucleus. Mol. Endocrinol. 5; 217-225, 1991.

21. Misrahi, M., Atger, M., d'Auriol, L., Loosfelt, H., Meriel, C., Fridlansky, F., Guiochon-Mantel, A., Galibert, F. and Milgrom, E.: Complete amino acid sequence of the human progesterone receptor deduced from cloned cDNA. Biochem. Biophys. Res. Commun. 143; 740748, 1987.

22. Moore, D. D., Marko, A. R., Buckley, D. I., Kapler, G., Payvar, F. and Goodman, H. M.: The first intron of the human growth hormone gene contains a binding site for glucocorticoid receptor. Proc. Natl. Acad. Sci. USA. 82; 699-702, 1985.

23. Muller, M. and Renkawitz, R.: The glucocorticoid receptor. Biochem. Biophys. Acta 1088; 171-182, 1991.

24. Nakane, P. K., Moriuchi, T., Koji, T., Tanno, M. and Abe, K.: In situ localization of mRNA using thyminethymine dimerized cDNA. Acta Histochem. Cytochem. 20; 229-243, 1987

25. Noguchi, T., Diesterhaft, M. and Granner, D.: Dibutyryl cyclic AMP increases the amount of functional messenger RNA coding for tyrosine aminotransferase in rat liver. J. Biol. Chem. 253; 1332-1335, 1978.

26. Payvar, F., DeFranco, D., Firestone, G. L., Edgar, B., Wrange, O., Okret, S., Gustafsson, J.-A. and Yamamoto, K. R.: Sequencespecific binding of glucocorticoid receptor to MTV DNA at sites within and upstream of the transcribed region. Cell 35; 381-392, 1983.

27. Renoir, J.-M., Radanyi, C., Jung-Testas, I., Faber, L. E. and Baulieu, E.-E.: The nonactivated progesterone receptor is a nuclear heterooligomer. J. Biol. Chem. 265; 14402-14406, 1990.

28. Roselli, C. E., West, N. B. and Brenner, R. M.: Androgen receptor and $5 \alpha$-reductase activity in the ductuli efferentes and epididymis of adult rhesus macaques. Biol. Reprod. 44; 739-745, 1991.

29. Sar, M., Lubahn, D. B., French, F. S. and Wilson, E. M.: Immunohistochemical localization of the androgen receptor in rat and human tissues. Endocrinol. 127; 3180-3186, 1990.

30. Scheidereit, C., Geisse, S., Westphal, H. M. and Beato, M.: The glucocorticoid receptor binds to defined nucleotide sequences near the promoter of mouse mammary tumor virus. Nature 304; 749-752, 1983.

31. Tai, P.-K., Maeda, Y., Nakao, K., Wakim, N. G., Duhring, J. L. and Faber, L. E.: A 59-kilodalton protein associated with protestin, estrogen, androgen, and glucocorticoid receptors. Biochemistry 25; 5269-5275, 1986.

32. Tsai, S. Y., Carlstedt-Duke, J., Weigel, N. L., Dahlman, K., Gustafsson, J.-A., Tsai, M.-J. and O'Malley, B. W.: Molecular interactions of steroid hormone receptor with its enhancer element: Evidence for receptor dimer formation. Cell 55; 361-369, 1988.

33. Tully, D. B. and Cidlowski, J.A.: pBR322 contains glucocorticoid regulatory element DNA consensus sequences. Biochem. Biophys. Res. Commun. 144; 1-10, 1987. 
34. Willmann, T. and Beato, M.: Steroid-free glucocorticoid receptor binds specifically to mouse mammary tumor virus DNA. Nature 324; 688-691, 1986.

35. Wilson, E. M., Lubahn, D. B., French, F. S., Jewell, C. M. and Cidlowski, J. A.: Antibodies to steroid receptor deoxyribonucleic acid binding domains and their reac- tivity with the human glucocorticoid receptor. Mol. Endocrinol. 2; 1018-1026, 1988.

36. Yamamoto, K. R.: Steroid receptor regulated transcription of specific genes and gene net works. Annu. Rev. Genet. 19; 209-252, 1985. 